\title{
A Study of Culture Dimensions, Organizational Ambidexterity, and Perceived Innovation in Teams
}

\author{
Raul Pelagio Rodriguez', Ma. Regina M. Hechanova²
}

\begin{abstract}
The impetus to innovate has emphasized the importance of organization's ability to both explore and explot new ideas or what is referred to as ambidexterity. This study examined ambidexterity as a predictor of teams' perception of their innovation. It also examined the impact of culture-power distance, uncertainty avoidance, collectivism, masculinity, and short-term orientation IT teams' explorative and exploitative behaviors. The results also show that team ambidexterity is a predictor of innovation. Power distance is negatively related to explorative behavior. Collectivist characteristics are positively associated with both explorative and exploitative behaviors. Masculine behavior likewise predict more explorative behavior. The results can guide human resource development efforts geared to foster greater innovation within teams in organizations.
\end{abstract}

Keywords: culture; power distance; uncertainty avoidance; collectivism; masculinity; explorative; exploitative; ambidexterity; innovation.

\footnotetext{
' John Gokongwei School of Management, Ateneo de Manila University, Katipunan Avenue, Loyola Heights, Quezon City, Philippines, I 100. Phone: +639 I8-9593228, e-mail: raul_P_rodriguez@yahoo.com

2 Department of Psychology, Ateneo de Manila University, Katipunan Avenue, Loyola Heights, Quezon City, Philippines, II00. Phone: +639l7874I4I84, e-mail: rhechanova@ateneo.edu
} 


\section{Introduction}

Globalization and rapid technological developments have given rise to a very competitive and challenging business environment. Enterprises have now to continually gain the competitive edge in terms of their products and services. In order to survive and excel, it has become an imperative for organizations to build and foster the capability to innovate. Heifetz and Linsky (2002) contend that to adapt to rapid changes, business leaders must foster organizational cultures that are adaptive and flexible. Others propose that an entrepreneurial mindset (Hsing and McDonough, 20II), a culture that supports risk taking (Munshi et al., 2005), and tolerates mistakes (Munshi et al., 2005) are also needed to support innovation.

Of late, there has been increasing attention on ambidextrous behavior and its impact on innovation. Ambidexterity is defined as the ability of leaders, teams, and individuals to be both explorative and exploitative. Explorative behavior is characterized by creativity, adventure, and risk taking. A person in an explorative mode produces a myriad of divergent ideas and as many as possible alternatives to problem solving or opportunity seeking. On the other hand, exploitative behavior is characterized by resultsorientation, systemization, and efficiency. Thus, in this mode a person synthesizes and seeks to converge ideas to arrive at an implementable action (Pandey and Sharma, 2009). Ambidextrous behavior can be exhibited both by the leadership of organizations as well as by teams within the organization. Case studies (O'Reilly, Tushman, 2004) have found ambidextrous behavior exhibited by the organization's leaders as well as by teams tasked to produce innovations.

Beyond the link between ambidexterity and innovation, Pandey and Sharma (2009) proposed the relationship of culture dimensions are linked to explorative and exploitative behaviors. However, their propositions have yet to be tested empirically. Thus, this study offers an empirical determination of how national culture influences ambidexterity and subsequently, innovation in teams .

\section{Organizational Ambidexterity}

Innovation is different from creativity. Creativity may produce a myriad of fresh and exciting ideas and new concepts. However, many companies fail because they are unable to turn ideas into a sustainable business (Sinar,Wellins, Pacione, 20II). Innovation brings these ideas to fruition by finding applications of these ideas that result into new products, processes, and services that redound to higher sales, market share, and/or profitability to the company. The distinction between creativity and innovation is important in the light of this study of explorative (more associated with creativity) and exploitative (more associated with idea implementation) behavior.

Given that innovation is defined as both the generation and implementation of new ideas, one construct that has come to fore to describe the ability to do both is organizational ambidexterity. Ambidexterity is the ability to simultaneously pursue exploitative and explorative behavior. Exploration is associated with experimentation, divergent thinking, and creativity. This is the ability found at the early stages of the innovation process involving the generation of new ideas and conceptualization. Exploration is characterized by risk-taking, discovery, and searching for new alternatives. Exploitative ability is generally employed at the latter stages of innovation when focus is on implementing and commercializing new ideas. Exploitation is associated with efficiency, convergent thinking, refinement, and improvement (Pandey and Sharma, 2009).

In their review of literature, Rosing et al. (20II) outlined two characteristics of innovative performance. First is that innovation consists of two activities, creativity and implementation. These are linked to exploration and exploitation, respectively. Second, the innovation processes are complex and nonlinear. Therefore, the organization has to constantly shift from exploration to exploitation and viceversa. These processes define the extent of ambidexterity in the organization.

In their case studies of 15 business companies in nine industries, O'Reilly III and Tushman (2004) revealed that companies that flourish over the long run demonwtrate both exploitative and explorative behaviors. They exploit existing capabilities and tweak its processes and products to come up with incremental innovations. At the same time, they look to the future and explore possibilities to achieve radical or breakthrough innovations. Thus, ambidexterity in an organization enables it to maintain and continually grow their traditional business as well as create innovations and new business lines.

ISSN: 07 I8-2724. (http://www.jotmi.org) 
Furthermore, the O'Reilly III and Tushman (2004) study considered the structure of the innovating organization in terms of the location of innovative teams. They found that companies tended to structure their breakthrough projects in one of four basic ways. "Some were carried out within existing functional designs, completely integrated into the regular organizational and management structure. Others were set up as cross-functional teams, groups operating within the established organization but outside the existing management hierarchy. A few took the form of unsupported teams, independent units set up outside the established organization and management hierarchy. However, most were pursued within ambidextrous organizations, where the breakthrough efforts were organized as structurally independent units, each having its own processes, structures, and cultures but integrated into the existing senior management hierarchy." It was found that ambidextrous organizations were more successful in producing breakthrough products than the other three structures.

Ambidextrous competencies are shared across hierarchical levels (Bledow et al., 2009; Chandrasekaran, 2009; Patterson et al.,n.d;and Probst et al.,20I I). The competencies involve balancing current and new activities, short- and longrange thinking, and engaging both in visioning and strategy execution. Top management grants autonomy (explorative) while staying involved (exploitative). Middle management provides a vision (explorative) while ensuring execution (exploitative). Line management embraces diversity (explorative) while acting together (exploitative).

Measuring organizational ambidexterity. Popadiuk (20I2) extended the concept of leadership ambidexterity to include other members of the organization. His study on organizational ambidexterity that involved 249 respondent companies in three economic sectors (trade, industry, and services), validated the presence of both explorative and explotative dimensions. Unfortunately, although Popadiuk (20I2) presented a useful measurement instrument for organizational ambidexterity, he did not directly relate ambidexterity with innovation.

The review of literature in the areas of organizational ambidexterity and innovation shows that, so far, there have been very few quantitative studies to validate the concept of ambidextrous organizational behavior and its impact on innovation. This study proposes to help fill this gap, by quantitatively validating the construct of ambidexterity and its influence on innovation.

\section{Culture and Innovative Behavior}

Beyond establishing the link between ambidexterity and innovation, this study explores the impact of culture. Culture is "the collective programming of the mind which distinguishes the members of one group or category of people from another" (Hofstede et al., 20I0). Several "layers of culture" (Hofstede et al., 20/0) can influence one's mental programming: national level, regional/ ethnic/religious/linguistic, gender, generation, social class, and organizational.

Findings from other studies point to how national culture is carried over into organizations to form or influence organizational culture that, in turn, determines the organization's inclination to innovate. Country cultural differences were found to affect leader effectiveness across cultures (Trompenaars and Hampden-Turner,2000) and work place practices (House et al., 2004; Hofstede et al., 20l0).

In their review of the literature, Pandey and Sharma (2009) identified common patterns and themes regarding the drivers that increase both exploratory and exploitative activities. These patterns led them to theorize a framework relating culture dimensions with organizational ambidexterity. Their conceptual framework suggests that national culture leads to explorative and exploitative behaviors. It is the ability to be both (organizational ambidexterity) that leads to innovation. Pandey and Sharma's model has yet to be supported quantitatively, which this study aims to achieve.

Figure I (prev. page) illustrates this study's proposed model.

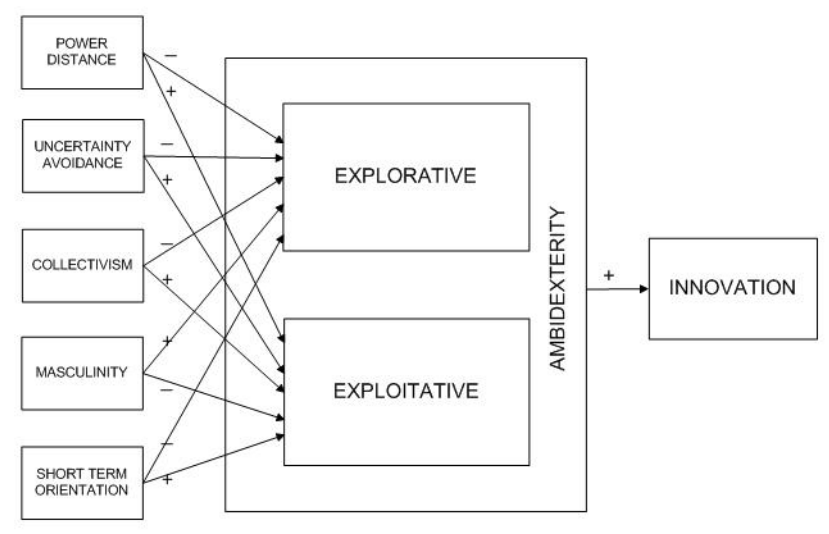

Figure I. The Proposed Culture-Ambidexterity and Ambidexterity-Innovation Model 
Specifically, this study examined four cultural attributes and their relationship with ambidexterity. Power distance is the extent to which power is distributed unequally with those with less power deferring to those with more power. In high power distance cultures, leaders tend to be autocratic and subordinates expect to be told what to do. Pandey and Sharma (2009) suggest that organizations high in power distance will be less likely to be exploratory but more likely to be exploitative.

In contrast to individualistic cultures where task prevail over relationships, in collectivist societies, there is a greater value of interdependence and harmony. Pandey and Sharma (2009) propose that organizations in individualistic cultures are more likely to be exploratory and exploitative.

Uncertainty avoidance is the extent to which the members of a culture try to avoid uncertain or unknown situations. Pandey and Sharma (2009) suggest that cultures high in uncertainty avoidance are less likely to be explorative but more likely to be exploitative.

Masculinity describes possessing qualities of aggressiveness, toughness, and logical analysis as against tenderness, concern for people and relationships, and concern for quality of life. Pandey and Sharma did not specifically argue for the relationship of masculinity and ambidextrous behavior. However exploration requires risk-taking, and exploitation requires the ability to implement. All of these requires the ability to put forth one's ideas and be aggressive. We thus suggest that masculinity will be associated with both exploratory and exploitative behaviors.

To summarize, this study tests the the two components of ambidextrous behavior as predicted by four cultural dimensions. Finally, it validates the positive relationship of ambidextrous behavior on innovation that been found in previous qualitative researches (Bledow et al., 2009; O'Reilly III and Tushman, 2004;Tushman and O' Reilly, 2004).
The following hypotheses are then proposed:

Hypothesis Ia: Power distance predicts explorative behavior inversely.

Hypothesis Ib: Power distance predicts exploitative behavior positively.

Hypothesis 2a: Collectivism predicts explorative behavior inversely.

Hypothesis 2b: Collectivism predicts exploitative behavior inversely.

Hypothesis 3a. Uncertainty avoidance predicts explorative behavior inversely.

Hypothesis 3b: Uncertainty avoidance predicts exploitative behavior positively.

Hypothesis 4a: Masculinity predicts explorative behavior positively.

Hypothesis 4b: Masculinity predicts exploitative behavior positively.

Hypothesis 5: Ambidexterity predicts perceived innovation.

\section{Method}

The study utilized a mixed-method sequential explanatory approach. For the quantitative analysis, an online survey was conducted involving information technology (IT) teams in business organizations involved in producing innovations in products or services. The survey measured innovation, ambidextrous team behaviors, and the five culture factors. The qualitative part consisted of interviewing executives from four companies that participated in the survey. The aim of the qualitative anaylsis was to shed light on the empirical findings and to elicit explanations for the findings.

\section{Participants}

The unit of analysis of the study was teams. Respondents were I) individuals who were members of teams from eleven IT companies engaged in enterprise systems development, mobile applications, systems maintenance, IT outsourcing, games development, among others and 2) individuals from teams in IT departments of six Philippinebased companies involved in telecommunications, education, and manufacturing. Selecting participants coming from one industry (Information Technology) was seen to minimize the possible confounding effect of variations due to the nature of business. At the same time, the IT industry in the Philippines has become a recent major economic and employment contributor. 
The participating IT teams were involved in developing and implementing IT applications for client companies, in the case of IT compamies, or for in-house use, in the case of IT departments. They employed traditional systems development methodologies, agile prototyping methodologies, or software package customization, depending on the needs of the client-users.

For first phase of the study, purposive sampling was made. An initial list was created based on personal contacts and the list of members of the Philippine Software Association of the Philippines. After initial contacts were made, introductory meetings were held with officers and CEOs of IT service providers and companies with IT departments. The purpose of the study was explained. It was also explained that the companies will not be identified by name in the final report. Although the study participants all come from Philippinebased companies, it is expected that cultural orientations, as well as explorative-exploitative behavior, may vary among companies due to different organizational cultures brought about by different management styles, corporate ownership, and structure. Sampling across a number of companies was done in order to highlight such variances.

The data used came from responses from 245 respondents comprising 56 teams from 17 companies. Teams were composed of three to thirteen members. Among these 189 were team members and 56 were team leaders. Teams consisted of 178 (73\%) male and $67(27 \%)$ female members. Their roles were programmers, Web developers, quality analysts, systems designers, project managers, business analysts, and mobile applications developers. Ages of respondents ranged from 19 to 53 years old, with an average of 27.2 .

In the second phase of the study, interviews were conducted with four executives from three participating companies. Executive $A$ is the CEO of a Web, mobile development and IT design company with around 50 IT professionals, male, in his 40's. Executive B is the CEO of an IT consulting and insourcing company dealing with enterprise systems with around 200 IT professionals, male, in his 30's. Executive $C$ is CEO of an IT consulting and staffing company with around 100 IT professionals, female in her 50's. Executive $D$ is a Senior Project Manager of a Web, mobile development and IT design company with around 50 IT professionals, male, in his 30's.

\section{Measures}

Innovation. Innovation is defined as both the creative generation of new ideas and the efficient implementation of selected ideas. Operationally, this study adapted the measurement scale developed by Ohly et al. (2006) and Zhou and George (200I). Innovation was measured using nine items describing the degree that novel and useful ideas are implemented at work. Reliability (Cronbach $\alpha$ ) of .94 was achieved.

Ambidexterity. Ambidexterity is defined as the ability to simultaneously pursue explorative and exploitative behavior. Explorative behavior is associated with creativity and divergent thinking. Exploitative behavior is associated with efficiency and convergent thinking. Popadiuk's (20I2) measure of ambidextrous behavior in organizations was used to measure ambidexterity. It originally consisted of 45 items but 8 items were dropped because they were deemd not applicable to the context. The ambidexterity score was derived by averaging explorative and exploitative scores.

Explorative behaviors. This subscale described how teams generate ideas, develop capabilities, and share and use knowledge. It was measured using 20 items such as the team's focus on new products, the extent of product or process innovation, participation in innovative alliances, and quest for new markets. Internal consistency reliability (Cronbach $\alpha$ ) of the explorative dimension was .90.

Exploitative behaviors. This subscale included 18 items describing whether the team is focused on strategic or operational matters, the team's dependence and relationships with outside partners, and efficiency. The internal reliability (Cronbach $\alpha$ ) of the exploiter dimension was .83.

Power distance. This is the extent to which the less powerful members of institutions and organizations within a country expect and accept that power is distributed unequally (Hofstede et al., 20l0). Operationally, it was measured using a 5-item scale developed by Yoo et al. (20II) Power distance items measured the extent to which the respondent agrees that decision making should be done by people in higher positions. Internal consistency reliability (Cronbach $\alpha$ ) was .84 .

Collectivism. Collectivism pertains to a situation in which people are integrated into strong, cohesive in-groups that protect them in exchange for unquestioning loyalty (Hofstede et al., 2010). Operationally, it was measured using a 5 -item scale developed by Yoo et al. (20I I). Collectivism items gauged whether group goals and welfare are more important than individual goals and welfare. Internal consistency reliability (Cronbach $\alpha$ ) was .82 . 
Uncertainty avoidance. This is the extent to which members of a culture feel threatened by uncertain or unknown situations and avoid such situations. This is expressed in a need for predictability and a need for written and unwritten rules (Hofstede et al., 2010). Operationally, this was measured using a 5-item scale developed by Yoo et al. (20l I). Uncertainty avoidance items measured the extent to which the team agrees that tasks, standards, and work procedures have to be well defined. Internal consistency reliability (Cronbach $a$ ) of the uncertainty avoidance scale was .87 .

Masculinity. This is associated with aggressiveness, toughness, task orientation as against femininity qualities of tenderness, concern for people and relationships, and concern for quality of life (Hofstede et al., 2010). Operationally, this was measured using a 4-item scale developed by Yoo et al. (20II). Masculinity items assessed respondent's agreement to statements that men perform tasks in a more rational and aggressive way than women. Internal consistency reliability (Cronbach $\alpha$ ) of the masculinity scale was .80 .

\section{Procedure}

E-mail messages were sent to the CEOs of target companies requesting their consent for the survey. After getting the consent of the heads of companies in his meetings with them, the researcher author received email addresses of nominated respondents from these companies. The researcher author then sent e-mail messages to the nominated respondents directing them to the online questionnaire in Google Survey.

Responses were tabulated and analyzed using SPSS. Confirmatory factor analyses and reliability testing were done. Descriptive statistics, correlations, and hierarchical regression analyses were used to test the study hypotheses.

Post-study interviews were held with four executives, whose profiles are described in an earlier section, in order to solicit feedback on the findings. During these meetings, the research author discussed the results of the survey with the executives. The executives were then asked whether they could relate the findings to the situations in their own companies. They were then asked whether they had any explanations for the findings.

\section{Results}

The study identified the team as the unit of analysis. Ratings for all items by members of each team were averaged to determine team ratings. Table I presents means, standard deviations, and the intercorrelations of all factors that were included in the analysis. Cronbach $\alpha$ values are shown in parentheses in the diagonal.

\begin{tabular}{lcccccccccccc}
\hline \multicolumn{1}{c}{ Variable } & M & SD & I & 2 & 3 & 4 & 5 & 6 & 7 & 8 \\
I. Power Distance & 2.13 & .45 & $(.84)$ & & & & & & & & \\
2. Uncertainty Avoidance & 4.18 & .28 & -.08 & $(.88)$ & & & & & & \\
3. Collectivism & 3.71 & .34 & .12 & $.41^{* *}$ & $(.81)$ & & & & & \\
4. Masculinity & 2.74 & .48 & $.55^{* *}$ & .20 & -.021 & $(.80)$ & & & & \\
5. Explorative & 3.70 & .36 & -.11 & $.28^{*}$ & $.40^{* * *}$ & .19 & $(.93)$ & & & \\
6. Exploitative & 3.36 & .29 & $.36^{* *}$ & $.29^{*}$ & $.44^{* *}$ & $.35^{* *}$ & $.55^{* *}$ & $(.83)$ & & \\
7. Ambidexterity & 3.53 & .29 & 0.11 & $.32^{*}$ & $.47^{* *}$ & $.30^{*}$ & $.91^{* *}$ & $.85^{* *}$ & $(.92)$ & \\
8. Innovation & 3.91 & .38 & -.18 & $.40^{* *}$ & $.42^{* *}$ & -.04 & $.71^{* *}$ & $.31^{*}$ & $.61^{* *}$ & $(.94)$ \\
\hline
\end{tabular}

**Correlation is significant at the 0.01 level (2-tailed).

*Correlation is significant at the 0.05 level (2-tailed).

Table I. Descriptive Statistics, Reliabilities, and Intercorrelation Matrix for the Study Variables 
The ambidexterity components of explorative and exploitative are significantly correlated with innovation, with explorative having a high correlation of .71. However, the correlations are not too high to suggest singularity. This strengthens the case for proceeding with regressing the two factors that comprise ambidexterity to innovation.

Uncertainty avoidance and collectivism correlate positively with innovation, explorative, and exploitative. Power distance and masculinity correlate positively with exploitative.

Ambidexterity correlates positively with innovation. This factor also correlates positively with uncertainty avoidance, collectivism, and masculinity.

A series of regression analyses were conducted to test the hypotheses. Results of the regression analyses are summarized in Figure 2. Detailed regression results are shown in Tables 2 and 3.

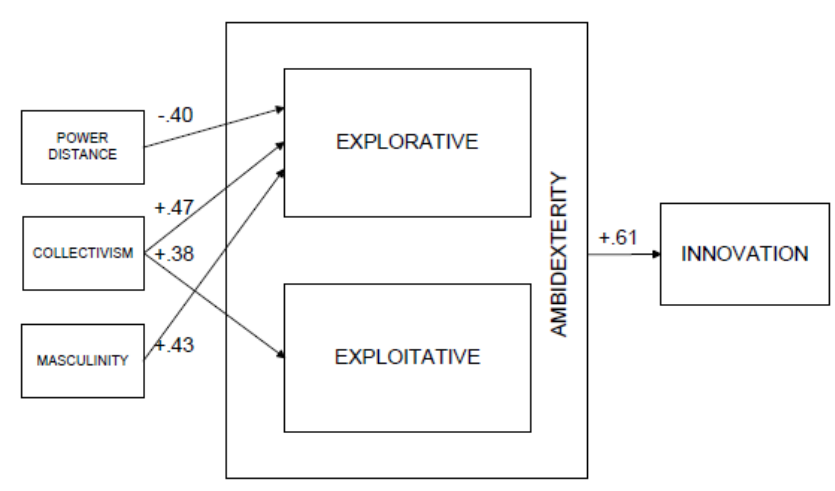

Figure 2. Regression Analyses Results

\begin{tabular}{|c|c|c|c|c|}
\hline \multirow[t]{2}{*}{ Model } & \multirow{2}{*}{\begin{tabular}{|l|} 
Unstandardized \\
Coefficients
\end{tabular}} & \multicolumn{2}{|c|}{ Standardized Coefficients } & \multirow[t]{2}{*}{ Sig } \\
\hline & & $\begin{array}{l}\text { Std. } \\
\text { Error }\end{array}$ & Beta & \\
\hline (Constant) & 1.87 & .71 & & .01 \\
\hline Power Distance & -.33 & .12 & -.40 & .01 \\
\hline Uncertainty Avoidance & -.04 & .18 & -.03 & .81 \\
\hline Collectivism & .49 & .143 & .47 & .00 \\
\hline Masculinity & .33 & .12 & .43 & .01 \\
\hline a. Dependent Variable: EXPLORATIVE & & & & \\
\hline
\end{tabular}

Table 2. Regression Coefficients. Power Distance, Uncertainty Avoidance, Collectivism, Masculinity as IVs and Explorative as DV

\begin{tabular}{|l|l|l|l|l|}
\hline Model & $\begin{array}{l}\text { Unstandardized } \\
\text { Coefficients }\end{array}$ & \multicolumn{2}{l|}{ Standardized Coefficients } & Sig \\
\hline & B & $\begin{array}{l}\text { Std. } \\
\text { Error }\end{array}$ & Beta & \\
\hline (Constant) & 1.06 & .54 & & .06 \\
\hline Power Distance & .13 & .09 & .20 & .17 \\
\hline Uncertainty Avoidance & .11 & .14 & .11 & .43 \\
\hline Collectivism & .32 & .11 & .38 & .01 \\
\hline Masculinity & .14 & .09 & .23 & .13 \\
\hline a. Dependent Variable: EXPLOITATIVE & & & & \\
\hline
\end{tabular}

Table 3. Regression Coefficients. Power Distance, Uncertainty Avoidance, Collectivism, Masculinity as IVs and Exploitative as DV

ISSN: 07 I8-2724. (http://www.jotmi.org)

Journal of Technology Management \& Innovation (c) Universidad Alberto Hurtado, Facultad de Economía y Negocios. 


\section{Power distance as affecting ambidexterity factors}

We hypothesized that the greater the power distance among teams, the less explorative are the teams. The results provide no basis for Hypothesis lb that states that the greater the power Distance, the more exploitative are the teams. Power Distance was found to be inversely predictive $(r=-.40, p=.01)$ of explorative behaviors but did not have a significant effect on exploitative behaviors.

One of the executives interviewed confirmed the negative effect of power distance on explorative behavior. "I have been in a mentoring, telling, and instructing mode all these years... and I can't get enough creativity from my teams.... I am undergoing a coaching training program and I think starting right away I will shift to a coaching mode."

\section{Collectivism as affecting ambidexterity factors}

Contrary to the expectation, that it is individualistic culture enabling explorative and exploitative behaviors, collectivism had positive effects on both explorative $(r=.47, p<.01)$ and exploitative $(r=.38, p<.01)$. A lady executive explained the positive influence of collectivism on being explorative. "My people like creating in groups. Filipinos have a high fear of failure. So they would rather hide behind the group when expressing ideas." She said that she would manage creativity in her organization by making them work in small groups. A senior project manager confirmed this and explained why "the more they think as a team, the more they are explorative". "They are creative but nahihiya magsabi (may be shy to express)." Individual ideas then become team ideas.

\section{Uncertainty avoidance as affecting ambidexterity factors}

Hypotheses $3 \mathrm{a}$ and $3 \mathrm{~b}$, predicts that uncertainty avoidance influences being explorative negatively and being exploitative positively. There was no support for this. Although uncertainty avoidance was positively correlated to both exploration and exploitation behaviors, they did not have unique contribution in predicting ambidexterity behaviors.

Masculinity as Affecting Ambidexterity Factors

Masculinity contributed significantly $(r=.43, p<.01)$ to explorative. This supports Hypothesis $4 \mathrm{a}$ that the more masculine characteristics there exist in the teams, the more explorative they are. However, there was no support for the effect of masculinity on exploitative behavior.
Taken together, the four culture variables accounted for .25 of the variance in explorative behavior in teams. However, of the four, only three are significant predictors namely power distance, collectivism, and masculinity. In predicting exploitative behavior, the variables accounting for 30 of the variance in exploitative behavior in teams. However, only one of the four, collectivism, was the only significant predictor of exploitative behavior.

\section{Ambidexterity as influencing perceived innovation}

We found support for our hypothesis that ambidexterity would be linked to team innovation. Ambidexterity which was the average of explorative and exploitative, was found to influence perceived innovation $(r=.61, p<.01)$, accounting for .36 of the variance in perceived innovation. An executive confirmed the need for ambidexterity in IT work, even in IT maintenance work, "Even if it's maintenace work where you have to be exploitative, you need creativity (explorative behavior) in solving problems that may arise."

\section{Discussion}

The results support a study hypothesis that the more that teams ascribe to superiors more authority and more power to decide, the less explorative they become. As explained by one executive, in such culture where CEOs closely mentor and feed decisions to the team, the teams are not creative. This provides the empirical and quantitative support to the proposition by Pandey and Sharma (2009) that organizations low in power distance will generate high exploratory innovaton. Findings, however, did not support the other proposition by Pandey and Sharma (2009) that organizations high in power distance will generate high exploitative innovation. However, the correlation between power distance and exploitation is significant. But when power distance is regressed alongside the other culture dimensions, it did not predict exploitative behavior uniquely. This results suggests that the other culture factors have a greater influence on exploitative behaviors in teams.

Results refuted the hypothesis and showed that the more collectivist the teams, the more explorative and exploitative teams are. To understand this finding, it is important to note that the study was conducted in the Philippines which is a highly collectivist country (Hofstede, 20I0). Thus, that teams have the tendency to exhibit both explorative and exploitative behavior as a group (collectivist) rather than as individuals. As the qualitative data suggests, in a collectivist environment individuals express ideas more freely within groups and at the same time work on implementing ideas together. An executive also noted that as opposed to Westerners who are more individualistic, Filipinos feel more comfortable expressing ideas within groups. 
The behavior of avoiding uncertain and unknown situations was not significantly related to either explorative or exploitative behavior. One explanation for this is that in the IT industry, project teams are almost always assigned the projects to develop and implement. The timetables are given based on dictates by the client. Specific methodologies are followed by the project teams. Project revenues are based on billing rates that are pre-agreed with the clients. In this context, therefore, whether or not the IT teams are risk averse may be irrelevant in relation to their being explorative or exploitative. The factor of uncertainty avoidance may be more relevant for certain functions and in industries other than the IT industry. This is something future studies can investigate.

A culture of masculinity - that of approaching problems logically than intuitively, of being aggressive, and of being more task than relationship oriented - is predictive of explorative behavior (Hypothesis 4a). In the context of teams, team members with "masculine" traits are likely to be more explicit in idea generation than team members with "feminine" traits. Although the correlation between the two variables was significant, masculinity did not significantly predict exploitative behavior. Rather, only collectivism predicted exploitative, indicating that it may influence exploitative behavior more than any other culture factor.

Finally, this study confirms that ambidextrous behavior is a predictor of innovation, as perceived by the teams that participated in the study. For companies to continually innovate, teams must exercise both explorative and exploitative behavior (Bledow et al., 2009; O'Reilly III and Tushman, 2004; Parthasarathy and Ariss, 20I I; Patterson et al., n.d.). The study fnding also lends quantitative support to the Rosing et al. (20I I) ambidexterity-innovation model that proposes that ambidexterity is an antecedent of innovation. An executive remarked that "in producing innovative products we need both creativity (explorative behavior) and discipline (exploitative behavior)."

The notion of ambidexterity resonates with adaptive leadership (Heifetz, R. A., 1994; Heifetz, R. A., Linsky, M., 2002), a practice of leadership that considers the situation of both leader and follower. There may be situations when decision-making is left to the followers, or team members, and situations when a controlling style is more appropriate. Adaptive leadership also considers the power distance factor in leadership, specifying that authority does not equal leadership. This resonates with this study's finding that power distance inversely affects creativity. Between the two ambidexterity components, explorative behavior correlated more highly with ambidextrous behavior than did exploitative behavior. This is a logical because the respondent teams rated themselves to be higher in explorative behavior than in exploitative behavior. That explorative behavior and exploitative behavior correlate significantly is consistent with the intertwining and mutual interdependence of these two constructs (Parthasarathy and Ariss, 20I I).

\section{Limitations of the study and further recommendations}

The companies that were sampled were chosen on the basis of the author having current contact with some officers of the Philippine Software Industry Association. These companies may not be homogenous in other factors, particularly structure and leadership factors, which could not be controlled during this study.

Also, most of the companies were purposely chosen to belong to one industry in order to minimize the possible confounding effect of different natures of business. Generalizability of the findings may be enhanced by further studies in other industries.

The concept of ambidexterity is more pronouncedly manifested over time, as innovative groups continually and iteratively explore and exploit as new products and processes are developed over the innovation life cycle. This study did not consider this time element, and therefore regarded ambidexterity characteristics as statically inherent within teams in the organization. How explorative and exploitative behaviors vary over the innovation life cycle can again be the subject of a longitudinal study.

The organizational location of innovative teams, whether they are part of the functional structure or located in a way that provides the team considerable autonomy, may influence explorer-exploiter characteristics. Further researches on this aspect are suggested.

This study's respondents, it should be noted, rated highly $(>3$ in a Likert scale of 5) in both explorative and exploitative attributes. While a formal determination of leadership approaches found in the companies that participated in the study was outside the scope of the study, it has been noted that the company heads, known to this author, have different leadership approaches and styles. These approaches may have influenced either explorative or exploitative behavior or both. This impact of leadership on ambidextrous behavior is suggested as a future research topic. 


\section{Significance of the study}

Management and human resource development programs point to various leadership and team characteristics that are claimed to be requisite factors for teams to innovate. This study provides empirical evidence that ambidextrous behavior - that is being both explorative and exploitative - enables team innovation. Furthermore, the results suggest that ambidextrous behavior appear to be influenced by cultural dimensions of power distance, collectivism, and masculinity.

For the leadership of organizations, particularly in the IT industry, the study findings substantiate the need for leadership that encourages both explorative and exploitative behaviors. The concept of ambidexterity is resonant with adaptive and flexible leadership/organization. Parthasarathy and Ariss (20lI) referred to innovation leaders as "controlled schizophrenics" and the dynamic capability of an innovative firm to "reconfigure resources" according to a changing environment. Tushman et al. (201I) suggested that firms thrive when a certain tension is maintained between the old (e.g., existing products or business) and the new (e.g., new product or business lines). Managing this constant creative conflict is referred to by Tushman et al. (20II) as "leading ambidextrously".

In the innovation life cycle, IT leaders should encourage exploration and discovery in the early conceptualization of projects and products. As these projects and products are defined, the IT leaders should then see to it that certain efficiencies are exploited to produce results. The quantitative and qualitative findings also suggest that IT leaders should develop in their teams both explorative and exploitative abilities, even in what is regarded as non-creative phases of IT work. In all IT aspects, leaders and teams have to be both explorative and exploitative particularly in problem solving, being explorative in generating alternative solutions and being exploitative in implementing chosen solutions.

Finally, there has been scarce research on quantitatively determing the effects of culture, ambidextrous behavioral orientation and innovation in teams. This study contributes to this particular body of knowledge. In particular, it emphasizes the need to understand and harness culture in order to enable innovation in teams.

\section{Biographical notes}

Raul P. Rodriguez is a Lecturer at the John Gokongwei School of Management of Ateneo de Manila University in Quezon City, Philippines. $\mathrm{He}$ is also an Adjunct Faculty Member at Enderun Colleges in Taguig City, Philippines. Raul obtained his PhD in Leadership Studies minor in Organizational Development at the Ateneo de Manila University. His professional career has been as Information Technology executive in several local and multinational companies. $\mathrm{He}$ is presently a management consultant for several companies.

Ma. Regina M. Hechanova is a Professor of Psychology at the Ateneo de Manila University in Quezon City, Philippines. She is the President of the Psychological Association of the Philippines and Chair of the Ateneo Department of Psychology. A human resource management and organization development consultant, her research interests include technology and organizations, innovation and organization transformation. 


\section{References}

AL-HUSSEINI, S, Elbeltagi, I. (20I2). The impact of leadership style and knowledge sharing on innovation in Iraqi higher educationilnstitutions. From Proceedings of the 4th European Conference on Intellectual Capital. Arcada University of Applied Sciences Helsinki Finland, 23-24 April 2012. Retrieved from http://academic-conferences.org/pdfs/ $\mathrm{ECICl}$ 2-book.pdf

BLEDOW, R., Frese, M., Anderson, N., Erez, M, and Farr, J. (2009). A dialectic perspective on innovation: Conflicting demands, multiple pathways, and ambidexterity. Industrial and Organizational Psychology: Perspectives on Science and Practice, 2(3), 305-337. Retrieved from http://www.siop. org/journal/siopjournal.aspx

CARDINAL, R.N., Aitken, M.R.F. (2006) ANOVA for the behavioral sciences researcher. New Jersey: Lawrence Erlbaum Associates.

CHANDRASEKARAN, A. (2009). Multiple levels of ambidexterity in managing the innovation- improvement dilemma: Evidence from high technology organizations. University of Minnesota. Retrieved from http://purl.umn. edu/54319

CHEN, G., Muller, A. (2010) Measuring Innovation from Different Perspectives. Published online in Wiley InterScience (www.interscience.wiley.com). Wiley Periodicals, Inc. doi: 10.1002/ert.20279

DAVIS, J.P., Eisenhardt, K. M. (20II) Rotating leadership and collaborative innovation: Recombination processes in symbiotic relationships. Administrative Science Quarterly, 56(2), |59-20I. doi: I0.1 I77/000|8392| |428|3|

DUTTA, S. (20/2). The Global Innovation Index 2012. France: INSEAD \&World Intellectual Property Organization. Retrieved from http://www.wipo.int/edocs/pubdocs/en/ economics/gii/gii_20I2.pdf

GARCIA-MORALES, V. J., Jiménez-Barrionuevo, M. M., Gutiérrez-Gutiérrez, L. (20I2). Transformational leadership influence on organizational performance through organizational learning and innovation. Journal of Business Research, 65, 1040-1050. Retrieved from http://www. sciencedirect.com/science/article/pii/SO I 482963I I00I007

GATIGNON,H.,Tushman, M.L.,Smith,W.,Anderson, P.(2002). Approach to assessing innovation: Construct development of innovation locus, type, and characteristics. Management Science, 48(9), II03-II22. Retrieved from https://flora. insead.edu/fichiersti_wp/inseadwp200I/200I-97.pdf
GOVINDARAJAN, V., Kopalle, P. K. (2006). Disruptiveness of innovations: Measurement and an assessment of reliability and validity. Strategic Management Journal, 27, 189-199. doi: I0.1002/smj.5। I

GUMUSLUOGLU, L., Ilsev, A. (2009). Transformational leadership, creativity, and organizational innovation. Journal of Business Research, 62, 46I-473. doi:10.1016/j. jbusres.2007.07.032

GUMUSLUOGLU, L., Ilsev, A. (2009). Transformational leadership and organizational innovation: The roles of external and internal support for innovation. The Journal for Product Innovation Management, 26, 264-277. Retrieved from http://www.academia.edu/4532487/Transformational_ Leadership_and_Organizational_Innovation_The_Roles_ of_Internal_and_External_Support_for_Innovation.

GUPTA,P. (20II). Leading innovation change - The Kotter way. International Journal of Innovation Science, 3(3), I4I-I50.

HECHANOVA, M. R. M., Escaler, M., Galamay, M.V., and Rodriguez, R.P. (20I0). Innovation in Philippine organizations. Center for Organizational Research and Development. Ateneo de Manila University. Unpublished.

HEIFETZ, R. A. (1994). Leadership without easy answers. Cambridge, Ma.: Harvard University Press.

HEIFETZ, R. A., Linsky, M. (2002). Leadership on the line. Boston, Ma.: Harvard Business School Publishing.

HOFSTEDE, G., Hofstede, G. J., Minkov, M. (20 I0). Cultures and organizations: Software of the mind: Intercultural cooperation and its importance for survival. U.S.A.: McGraw-Hill.

HOUSE, R.J. et al. (eds.). (2004). Culture, leadership, and organizations:The GLOBE study of 62 societies. Thousand Oaks, CA: Sage Publications, Inc.

HSING-ER Lin. (20I0). Effects of strategy, context, and antecedents and capabilities on outcomes of ambidexterity. Netherlands: CenER, Tilburg University.

HSING-ER Lin, McDonough III, E. F. (20II) Investigating the role of leadership and organizational culture in fostering innovation ambidexterity. IEEE Transactions on Engineering Management, 58(3), 497-509. doi: 10.1109/ TEM.20 I 0.209278 I 
JANSEN, J.J.P., Vera, D., Crossan, M. (2009). Strategic leadership for exploration and exploitation:The moderating role of environmental dynamism. The Leadership Quarterly, 20,5-18. doi: 10.1016/j.leaqua.2008.11.008

KOTTER, J. P., Cohen, D.S. (2002). The heart of change. Boston: Harvard Business School Press.

MOKHBER, M., Wan Ismail, W.K., Vakilbashi, A. (20I I). The impact of transformational leadership on organizational innovation moderated by organizational culture. Australian Journal of Basic andApplied Sciences, 5(6),504-508. Retrieved from http://connection.ebscohost.com/c/articles/65068883

MUNSHI, N., Oke,A., Ouranam, P., Stafylarakis, M., Towells, S., Moeslein, K., and Neely, A. (2005). Leadership for Innovation: Summary Report from an AIM Management Research Forum In cooperation with the Chartered Management Institute Engineering and Physical Sciences Research Council. March 2005. Retrieved from http://www.aimresearch.org/ uploads/File/Publications/Academic\%20Publications\%202/ Leadership_for_Innovation.pdf

OHLY, S., Sonnentag, S., \& Pluntke, F. (2006). Routinization, work characteristics and their relationships with creative and proactive behaviors. Journal of Organizational Behavior, 27, 257-279. doi: 10.1002/job.376

O'REILLY III, C. A., Tushman, M. L. (2004) The ambidextrous organization. Harvard Business Review, April 2004, 74-8I.

PANDEY, S., Sharma, R. R. K. (2009). Organizational factors for exploration and exploitation. Journal of Technology Management and Innovation, 4(I), 48-58. http://dx.doi. org/I0.4067/S07/ 8-27242009000I00005

PARTHASARATHY, R., Huang, C., Ariss, S. (201 I). Impact of dynamic capability on innovation, value creation and industry leadership.The IUP Journal of Knowledge Management, 9(3). http://dx.doi.org//0.2478/oam-2013-0038

PATTERSON, F., Kerrin, M., Gatto-Roissard, G. (n.d.) Characteristics \& behaviors of innovative people in organisations: Literature review.A paper prepared for NESTA Policy and Research Unit (NPRU). London: City University.

POPADIUK, S. (20I2) Scale for classifying organizations as explorers, exploiters or ambidextrous. International Journal of Information Management, 32, 75-87. doi:10.1016/j. ijinfomgt.20II.07.00I
PROBST, G., Raisch, S., Tushman, M.L. (20I I). Ambidextrous leadership: Emerging challenges for business and HR leaders. Organizational Dynamics, 40, 326-334. doi:10.1016/j. orgdyn.2011.07.010

QUINN, R.E., Faerman, S. R., Thompson, M. P., McGrath, M. R. (2003). Becoming a master manager: A competency framework. New York: John Wiley \& Sons, Inc.

ROSING, K., Frese, M., Bausch, A. (20II). Explaining the heterogeneity of the leadership-innovation relationship: Ambidextrous leadership. The Leadership $\mathrm{Q}$ u a rterly, 22(5), 956-974. doi:10.1016/j.leaqua.20II.07.014

ROST, J. C. (1993). Leadership for the twenty-first century. Praeger Publishers, Westport, CT.

SCHEIN, E. H. (1996). Culture: the missing concept in organization studies. Administrative Science Quarterly, 4I, 229-240. doi: 10.2307/23937/5

SCHEIN, E.H. (2004). Organizational cuture and leadership. CA: Jossey-Bass.

SINAR, E.F., Wellins, R.S., Pacione, C. (20II). Creating the conditions for sustainable Innovation. Development Dimensions International. Retrieved from http://www. ddiworld.com/DDIWorld/media/trend-research/ creatingtheconditionsforsustainableinnovation_tr_ddi.pdf

SIPOS, G.L. (2009). Measuring the innovation projects effectiveness. Megatrend Review, 6(2), 229-238.

TOKARCZYK, T., Appelman, J. (2008). The corporate life cycle: Leading organizations to perpetual life. FMI Quarterly, 4, 52-6I. Retrieved from http://www.fminet.com/media/pdf/ quarterly/2008_4_whole_issue.pdf

TROMPENAARS, F., Hampden-Turner, C. (2000). Riding the waves of culture. London: Nicholas Brealey Publishing.

TUSHMAN, M. L., Smith, W. K., Binns, A. (20II). The ambidextrous CEO. Harvard Business Review. 89(6), 74-80.

USSAHAWANITCHAKIT, P. (20II). Moderating effects of environment on the strategic leadership, organizational learning, innovation, and performance relationships. Journal of International Business and Economics, I I (2), 45-55.

WANG, C. L. (2010). The Role of Ambidextrous Organizational Culture in Resolving the Exploration Exploitation Paradox in New Product Innovation. Presented in the Institute for Small Business and Entrepreneurship Conference, 2010, London. 
WANG, C. L., Rafiq, M. (2009). Organizational diversity and shared vision: resolving The paradox of exploratory and exploitative learning. European Journal of Innovation Management, I2(I), 86-10I. doi: I0.1 108/I46010609/0928/84

WANG, C.L., Rafiq, M. (20I3). Ambidextrous organizational culture, contextual ambidexterity and new product innovation : a comparative study of UK and Chinese hightech firms. British Journal of Management, 25(I), 58-76. doi: I0.IIII/j. I467-855I.20I2.00832.x

YOO, B. Donthu, N., Lenartowicz, T. (20II). Measuring Hofstede's five dimensions of cultural values at the individual level: Development and validation of CVSCALE. Journal of International Consumer Marketing, 23, 193-210, 2011. Doi: 10.1080/0896|530.201।.578059

ZHENG,W.,KhouryA.E.,and Grobmeier,C.How doleadership and context matter in R\&D team innovation? - A multiple case study. Human Resource Development International, 13(3), 265-283. doi: $10.1080 / 13678868.2010 .483816$

ZHOU, J., \& George, J. M. (200I). When job dissatisfaction leads to creativity: encouraging the expression of voice. Academy of Management Journal, 44(4), 682-696. Retrieved from http://opeconomica.files.wordpress.com/201 I/I0/ when-job-dissatisfaction-leads-to-creativity.pdf 